\title{
Discussions on Lightning Protection Methods in Solar Water Heater System
}

\author{
Wei He ${ }^{*}$, Lei Xie, Wenpe Li \\ School of Physics and Electronic Information, Yunnan Normal University, Kunming, 650500, China
}

*Corresponding author: he99wei@aliyun.com

Keywords: Lightning, Protection Method, Solar Water Heater, Safety

\begin{abstract}
Because of the situation of the solar water heater systems, it is aiming at safety of the current of lightning protection from the hazards of them. From the structure and working principle of solar water heaters and the way of lightning introduction, the paper discussed the protection methods of direct lightning and inductive lightning, as well as shielding and equipotential bonding methods. These methods can effectively reduce and avoid the occurrence of lightning strikes, and provide a comprehensive lightning protection construction method for installing solar water heaters. According to the number of water heaters and the way of laying, the lightning rod or lightning protection belt can be flexibly used for protection. While using lightning rods or lightning protection belts for lightning protection, it is also necessary to consider equipotential bonding by means of lightning protection facilities of buildings. This can be easy to install and cost-effective. These methods can be considered, the safety hazards of solar water heaters can be effectively reduced.
\end{abstract}

\section{Introduction}

Lightning flash is a common natural phenomenon. Due to its time is very short and the mammoth current magnitude, lightning discharge will produce tremendous magnetic and radiation field changes. The huge energy could interfere with the radio communication, and even beak down the communication system and the solar water heater systems [1-3]. Solar energy is one of the cleanest energy sources currently. With the improvement of consumers' environmental protection and green awareness, more and more solar water heaters have been installed on the roof. However, from the lightning protection safety tests, it was found that most of the lightning protection measurements for solar water heaters are not well done, and that is very dangerous for the people and instruments. Because the lighting device of the water heater is often installed at the unobstructed height of the roof, it is easy to be struck by lightning when thundering. The powerful lightning current would invade the room along the path of the power line and metal conduit. It will endanger the safety of people and property [4]. This paper discussed the lightning protection measurements for solar water heaters.

\section{Structure and Working Principle of Solar Water Heater}

Basic structure: The solar water heater is mainly composed of three parts: a heat preservation water tank, a glass vacuum heat collecting tube and a bracket, and also includes upper and lower circulating water pipes, intelligent instruments and some corresponding accessories. The water tank shell and bracket are mostly metal products, which are generally placed at the highest point of the building and are more susceptible to lightning strikes.

Working principle: As shown in Figure 1, the solar water heater is a photothermal converter. Its vacuum tube is the core component. It is structured like an elongated thermos bottle. There is a vacuum between the inner and outer layers. A spectrally selective absorption layer is coated on the surface of the inner glass tube by a special process. That is used to absorb solar radiation energy to the greatest extent. After exposure to sunlight, photons hit the coating and then solar energy is converted into heat. After the water absorbs heat from the outside of the coating, the water temperature rises and the density decreases. Hot water flows upward from the upper circulation pipe 
into the insulated water tank, and the significant cold water drops. At the same time, the tap water flows downward from the lower circulation pipe as a supplement, and the hot water is always in the upper part, that is, in the water tank [2, 3].

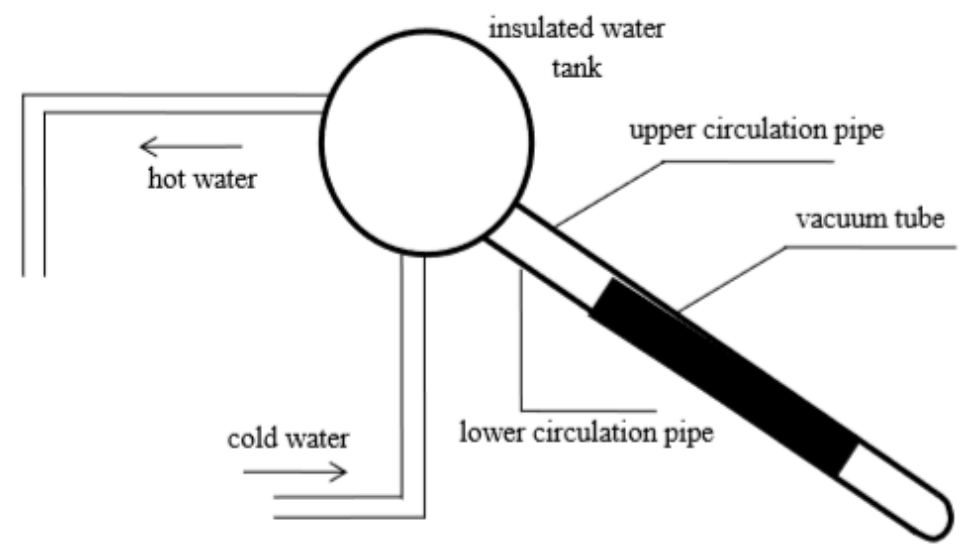

Fig.1. Principle of solar water heaters

\section{Classification of Lightning}

The ball $R=21.6 \mathrm{~mm}, m_{b}=45 \mathrm{~g}$. To ensure the cue ball and pick and not run into low contact choose other parts of the cue for $w=16 \mathrm{~mm}$. From the law of conservation of energy, it is known that the lighter lift stick, the faster the speed at first, consider to pick cue the deformation of stress intensity factor, finally optimization for $m_{c}=34 \mathrm{~g}$. Since robot have play ball institutions, in order not to decorate with the wheel position conflict, only can pick the ball in play on electromagnetic valve electromagnet institutions. According to the electromagnet diameter and robot's height, take $L=58 \mathrm{~mm}, h=19 \mathrm{~mm}$.

Lightning can be divided into direct lightning and induction lightning according to its formation mechanism. As shown in Figure 2 [4].

The direct lightning strike is a strong discharge with the ground target when the charged cumulonimbus clouds approach the ground to a certain extent. Although the probability of direct lightning strikes is small, its harm is extremely great, so it cannot be taken lightly.

Inductive lightning is divided into electrostatic induction lightning and electromagnetic induction lightning. Static induction lightning: Charged cumulus clouds induce a large amount of charge on overhead line conductors or other top-to-point projections. After the charged cumulus cloud and other guests discharge, the induced charge loses its bondage. Propagating along line conductors or conductive projections in the form of large current, high voltage shock waves. Electromagnetic induction lightning: When lightning is discharged, a huge impact lightning current generates a rapidly changing strong magnetic field in the surrounding space. Adjacent conductors induce high induced electromotive forces in strong magnetic fields. Although the damage of the inductive thunder is not as straight as the thunder, the damage is often the core device of the device.

$$
\text { Lightning }\left\{\begin{array}{l}
\text { direct lightning(Lightning flows directly through the target) } \\
\text { induction lightning }\left\{\begin{array}{l}
\text { electromagnetic induction lightning } \\
\text { Inductive current or induced electromotive } \\
\text { force generated in a circuit near a lightning strike }
\end{array}\right) \\
\text { electrostatic induction lightning } \\
\text { (Lightning current propagates along metal lines) }
\end{array}\right.
$$

Fig.2. Classification of thunder and lightning 


\section{Direct Lightning Protection for Solar Water Heaters}

For lightning strikes, the independent lightning rod and the frame lightning rod are generally used for protection. Its mechanism is divided into lightning receptors (for lightning, including lightning rods, lightning protection nets and lightning protection belts), down conductors (lightning current from the lightning receptor to the grounding device) and grounding devices.

\subsection{Single Lightning Rod Method.}

In the case of a single lightning rod, the protection range of the solar water heater can be determined by the rolling ball method. As shown in Figure 3, $R$ is a solar water heater and the height is $h_{\mathrm{x}}$, the lightning rod is perpendicular to the plane, and the height is $h$. According to the Code for Lightning Protection of Buildings (GB 50057-94) Appendix IV. When the height of a single lightning rod is less than or equal to the radius hr of the ball, the ground protection radius is determined by the following formula.

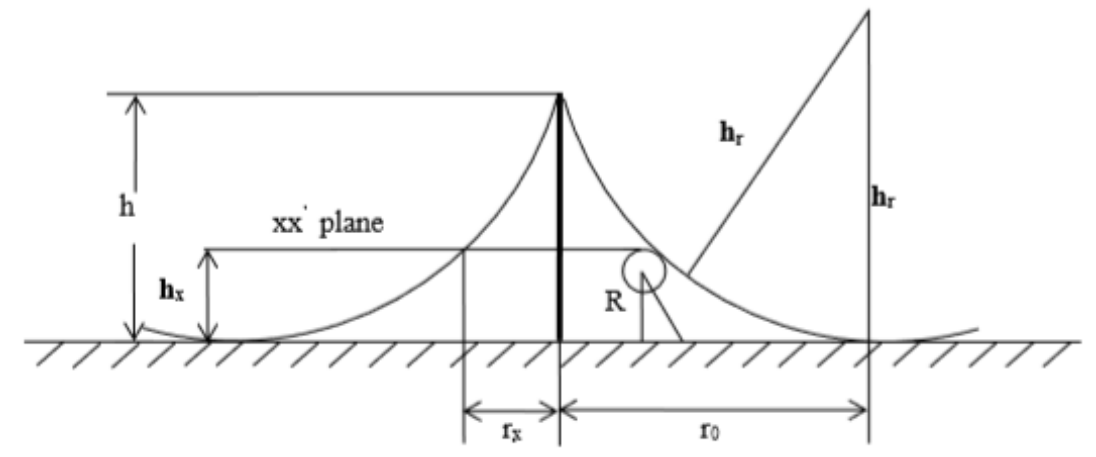

Fig.3. A single lightning rod protection for solar water heaters

$$
r_{x}=\sqrt{h\left(2 h_{r}-h\right)}-\sqrt{h_{x}\left(2 h_{r}-h_{x}\right)}
$$

When the height of the protected object is $h_{\mathrm{x}}=0$

$$
r_{x}=\sqrt{h\left(2 h_{r}-h\right)}
$$

Where $r_{x}$ is the protection radius of the lightning rod on the $\mathrm{xx}^{\prime}$ plane of the $h_{\mathrm{x}}$ height; $r_{0}$ is the protection radius of the lightning rod on the ground; $h_{\mathrm{r}}$ is the radius of the ball; $h_{\mathrm{x}}$ is the height of the object to be protected.

\subsection{Lightning Strip Method.}

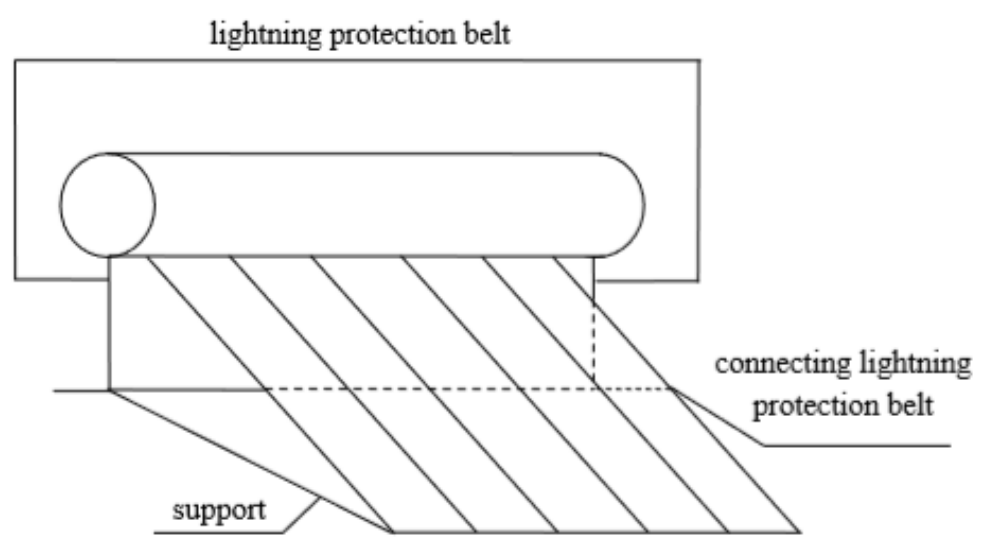

Fig.4. Lightning belt protection for solar water heaters

According to the length of the water heater tank is $1.5 \mathrm{~m}$ and the bracket of the water heater is a metal conductor and has good electrical conductivity. The water heater's own materials should be 
fully utilized to reduce costs. In this case, we only need to use $\Phi 8$ galvanized round steel on the water heater tank. As shown in Figure 4. The two ends of the round steel are welded to the water heater bracket, and then the water heater bracket and the lightning protection belt are connected at two points. Comparing the above two methods, the lightning protection belt method is more economical than the vertical lightning rod, and the operation is simple.

Equipotential bonding: Article 312 of the Code for Lightning Protection of Buildings (GB50057294, 2005 Edition) [5]. If the object whose protruding roof is higher than the lightning receptor is metal, it should be connected to the roof lightning protection device. If it is a non-metallic object, it should be within the protection range of the lightning receptor. Otherwise, the lightning receptor should be installed for protection.

Single lightning rod method: In the middle position of multiple water heaters on the flat roof, and set a single lightning rod at $3 \mathrm{~m}$ from each water heater. The height of the lightning rod can be determined according to the formula (1). Such a treatment method is more cost-effective than using a lightning protection belt.

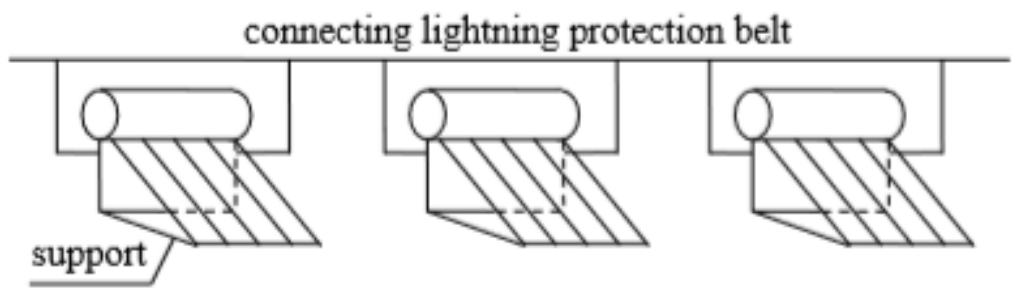

Fig.5. Lightning belt protection for several solar water heaters

Lightning strip method: When multiple water heaters are arranged in a straight line on the ridge, a lightning protection belt can be used to connect the water heaters to each other. This protection method is feasible and economical. As shown in Figure 5, two support cards are welded upwards on the bracket of each water heater, and welded to the lightning protection belt of the water heater, and then the two ends of the lightning protection belt are connected with the roof lightning protection belt [6].

\section{Induction Lightning Protection for Solar Water Heaters}

Use shielded pipe and shielded wire: Shield the incoming and outgoing electrical lines and route the control lines through the metal tubes. Or use a shielded wire with a metal shield to lay the line, and ground the metal pipe (slot) and the shield at both ends.

Equipotential bonding: Set the local equipotential bonding terminal block in the shower room (LEB). Connected LEB with metal pipes, metal objects, building metal ribs, line shields and electrical PE grounding. This can form an equipotential body inside the room to protect the safety of people and equipment.

Install the socket arrester: The control system of the solar water heating system is connected to the power line. The overvoltage is easy to damage the indoor control system, and the socket arrester can be installed at the power supply end of the solar water heating system. The grounding of the arrester is connected to the LEB.

Block water source conduction: In order to prevent lightning from being conducted along the water source, it should be connected with an insulated pipe between the indoor water supply pipe and the solar water supply pipe, and installed a valve at both ends to control the flow direction of the water. We vent the water in the insulating tube through the valve when the water heater is not used, thus blocking the lightning current and the electromagnetic wave conduction path [7].

\section{Conclusion}

Through the study of the magnetic field around the lightning, we can provide the data about the lightning protection of the safety distance and the parameters of the lightning protection device selection, etc.. This paper started to state with the structure and working principle of the water 
heater. And it combined the lightning attraction to discuss the protection of direct lightning and inductive lightning as well as shielding and equipotential bonding. According to the number of water heaters and the way of laying, the lightning rod or lightning protection belt can be flexibly used for protection. While using lightning rods or lightning protection belts for lightning protection, it is also necessary to consider equipotential bonding by means of lightning protection facilities of buildings. This can be easy to install and cost-effective. In the design and construction of buildings, if the above measures can be considered, the safety hazards of solar water heaters can be effectively reduced, and the problems caused by the subsequent lightning protection measures can be reduced.

\section{Acknowledgements}

This project was supported by National Natural Science programs (51267021) and College students' innovative entrepreneurial training programs (2015).

\section{References}

[1] M.J.Master, M.A.Uan. Lightning induced voltages on power lines theory [J]. IEEE Trans. Power Apparatus Syst, 1984, 103 (02): 502-518.

[2] M.A.Uman, D.K.McLain, E.P.Krider. The electromagnetic radiation from a finite antenna [J]. Amer. Phys, 1975, 43 (7): 33-38.

[3] Wei He, Pi-Cui Zhang. Soil resistivity lightning current model [J]. Applied Mechanics and Material, 2013, 403 (3): 2116-2119.

[4] Chen Rui, Talking about the hidden dangers of lightning protection of solar water heaters and their solutions [J]. Journal of Guangxi University of Technology. 2006, 17 (suppl. 1): 24-26.

[5] Zhang Xiaowen, Meng Shanliang, Discussion on lightning protection of solar water heaters [J]. Inner Mongolia Meteorology, 2017, (4): 48.

[6] Chen Xiangmin. Lightning protection measures for sloping roof residential solar water heaters [J]. Solar Energy, 2002, (6): 15-16.

[7] Chen Xiaowei, Lightning basic knowledge and lightning protection design [J]. Science and Technology Information, 2007, (06):57-63. 